\title{
Reproduction-related sound production of grasshoppers regulated by internal state and actual sensory environment
}

\author{
Ralf Heinrich $^{1}$ *, Michael Kunst ${ }^{2}$ and Andrea Wirmer ${ }^{3}$ \\ 1 Department of Cellular Neurobiology, Institute for Zoology and Anthropology, University of Göttingen, Göttingen, Germany \\ 2 Department of Cellular and Molecular Physiology, Yale School of Medicine, New Haven, CT, USA \\ ${ }^{3}$ Institute for Neurobiology, University of UIm, UIm, Germany
}

Edited by:

Björn Brembs, Freie Universität

Berlin, Germany

\section{Reviewed by:}

Varvara Vedenina, Russian Academy of Sciences, Russia

María-Dolores García, Universidad de Murcia, Spain

\section{*Correspondence:}

Ralf Heinrich, Department of Cellular Neurobiology, Institute for Zoology and Anthropology, University of Göttingen, Berliner Strasse 28

Göttingen, Germany.

e-mail:rheinri1@gwdg.de
The interplay of neural and hormonal mechanisms activated by entero- and extero-receptors biases the selection of actions by decision making neuronal circuits. The reproductive behavior of acoustically communicating grasshoppers, which is regulated by short-term neural and longer-term hormonal mechanisms, has frequently been used to study the cellular and physiological processes that select particular actions from the species-specific repertoire of behaviors. Various grasshoppers communicate with species- and situationspecific songs in order to attract and court mating partners, to signal reproductive readiness, or to fend off competitors. Selection and coordination of type, intensity, and timing of sound signals is mediated by the central complex, a highly structured brain neuropil known to integrate multimodal pre-processed sensory information by a large number of chemical messengers. In addition, reproductive activity including sound production critically depends on maturation, previous mating experience, and oviposition cycles. In this regard, juvenile hormone released from the corpora allata has been identified as a decisive hormonal signal necessary to establish reproductive motivation in grasshopper females. Both regulatory systems, the central complex mediating short-term regulation and the corpora allata mediating longer-term regulation of reproduction-related sound production mutually influence each other's activity in order to generate a coherent state of excitation that promotes or suppresses reproductive behavior in respective appropriate or inappropriate situations. This review summarizes our current knowledge about extrinsic and intrinsic factors that influence grasshopper reproductive motivation, their representation in the nervous system and their integrative processing that mediates the initiation or suppression of reproductive behaviors.

Keywords: reproductive behavior, reproductive states and readiness, sound production, grasshopper, neurotransmitters and hormones, central complex, corpora allata

\section{INTRODUCTION TO THE MATING BEHAVIOR OF ACOUSTICALLY COMMUNICATING GRASSHOPPERS}

The mating behavior of acoustically communicating grasshoppers (Orthoptera, Acrididae, Gomphocerinae) has been subject to various scientific investigations for some decades. Especially the subgroup Gomphocerinae contains numerous species that generate communication signals by hind leg stridulation and/or wing clapping (Elsner, 1974; Elsner and Wasser, 1995; Lorier et al., 2010). The most complete set of data concerned with the generation, perception, and nervous processing of the species- and context-specific songs has been established in the species Chorthippus biguttulus, in which both males and females are capable of sound production by hind leg stridulation.

Mature male C. biguttulus generate calling songs to attract females, courtship songs to establish female readiness for copulation and rival songs in situations of competition with other males (von Helversen and von Helversen, 1975). In contrast, females only sing in the state of active reproductive readiness that is regulated by maturation, previous mating experience, and oviposition cycles (Wirmer et al., 2010). All songs contain individual song sequences
(2-6 s duration) consisting of repetitions of a species-specific basic subunit ("chirp"; $50-70 \mathrm{~ms}$ duration) that is typically generated by three up- and down-movements of a hind leg (von Helversen, 1972; Elsner, 1974).

Acoustic signals are generated by scraping a row of pegs on the insides of the hind legs against a prominent cuticular vein on the front wings (=stridulation). Rhythmicity of stridulatory hind leg movements that determines the species-specific temporal acoustic patterns is generated by rhythm generating circuits in the metathoracic ganglion complex (Ronacher, 1989; Hedwig, 1992). Each of the hind legs is driven by a hemiganglionic network and rightleft coordination is maintained by a set of connecting neurons (Ronacher, 1989; Heinrich and Elsner, 1997). Stridulation is initiated and maintained by command neurons that connect the brain with the thoracic rhythm generators (Hedwig, 1994). Each type of command neuron invariantly activates only one song pattern from a species' repertoire (Hedwig and Heinrich, 1997). Thus, the command neurons transmit the activating signal from the brain to the thoracic pattern generators but brain neuropils located presynaptically to the command neurons mediate the decision about when 
and which pattern to sing. Studies on grasshoppers including the species $C$. biguttulus and on other insects indicated that the decision about time, type, and intensity of stridulation is mediated by the central complex (Heinrich et al., 1997,2001; Popov et al., 2005). This set of midline-spanning neuropils has been demonstrated to process multimodal sensory information (visual, acoustic, and probably others) in order to select one and inhibit other conflicting sensorimotor pathways that compete for behavioral expression (Wessnitzer and Webb, 2006).

The occurrence and intensity of grasshopper songs in response to male calling songs (to stimulate females) or female songs (to stimulate males) has been used as a measure of an individual's reproductive readiness (von Helversen, 1972; von Helversen and von Helversen, 1997; Wirmer et al., 2010). Several environmental conditions (e.g., temperature, illumination, air pressure, ambient noise) and more specific signals (e.g., acoustic signals of conspecific grasshoppers or predators) have been shown to stimulate or inhibit grasshopper sound production on a rather short time scale in the range of seconds to minutes (Figure 1). In addition to this short-term regulation of reproduction-related sound production, other factors influence this behavior on a longer time scale ranging from hours to weeks. These factors include sexual maturity especially in females (Loher and Huber, 1964; Kriegbaum, 1988; Wirmer et al., 2010), female oviposition cycles (von Helversen, 1972), and previous mating activity of both males and females (Loher and Huber, 1964; Wirmer et al., 2010; Figure 1). Adjustment of reproductive behaviors to these behavioral states has been attributed to hormone signaling and particularly juvenile hormone $(\mathrm{JH})$ produced in the corpora allata has been implicated in the control of female grasshopper and other insects' reproductive motivation (Loher, 1962; Stout et al., 1991; Hartmann et al., 1994).
Grasshopper reproductive behavior including reproductionrelated sound production is regulated by both the actual situation and the internal physiological state. In the following, we present the current knowledge about the neural and endocrinal mechanisms that select reproductive behaviors and activate sound production in appropriate situations and outline possible mechanisms that adjust long-term and short-term regulatory mechanisms to provide coherent behavioral responses.

\section{"SHORT-TERM" REGULATION OF GRASSHOPPER SOUND PRODUCTION BY THE CENTRAL COMPLEX}

Pharmacological studies on restrained intact grasshoppers clearly indicated that the central complex selects and coordinates sound pattern generation in acoustically communicating species. These studies identified a number of transmitters that contribute to the processing of sensory information relevant for reproductive behaviors and hence participate in the decision about whether or not to sing in a particular situation and which pattern to produce. Sound production can be stimulated by focal injection into the central complex of acetylcholine and both nicotinic and muscarinic agonists (Heinrich et al., 1997), proctolin, and dopamine and it can be inhibited by $\gamma$-aminobutyric acid (GABA), glycine, and nitric oxide (Heinrich et al., 1998; Wenzel et al., 2005; Figure 2A). Except for glycine, the presence of these transmitters and some of their receptors in the central complex has been confirmed by immunocytochemical studies, suggesting that they function as endogenous signals in the processing of relevant sensory information and some of them could be associated with particular sensory input that promotes or inhibits sound production (see below).

Grasshopper sound production can also be elicited by pharmacological inactivation of inhibitory synaptic signaling in the central

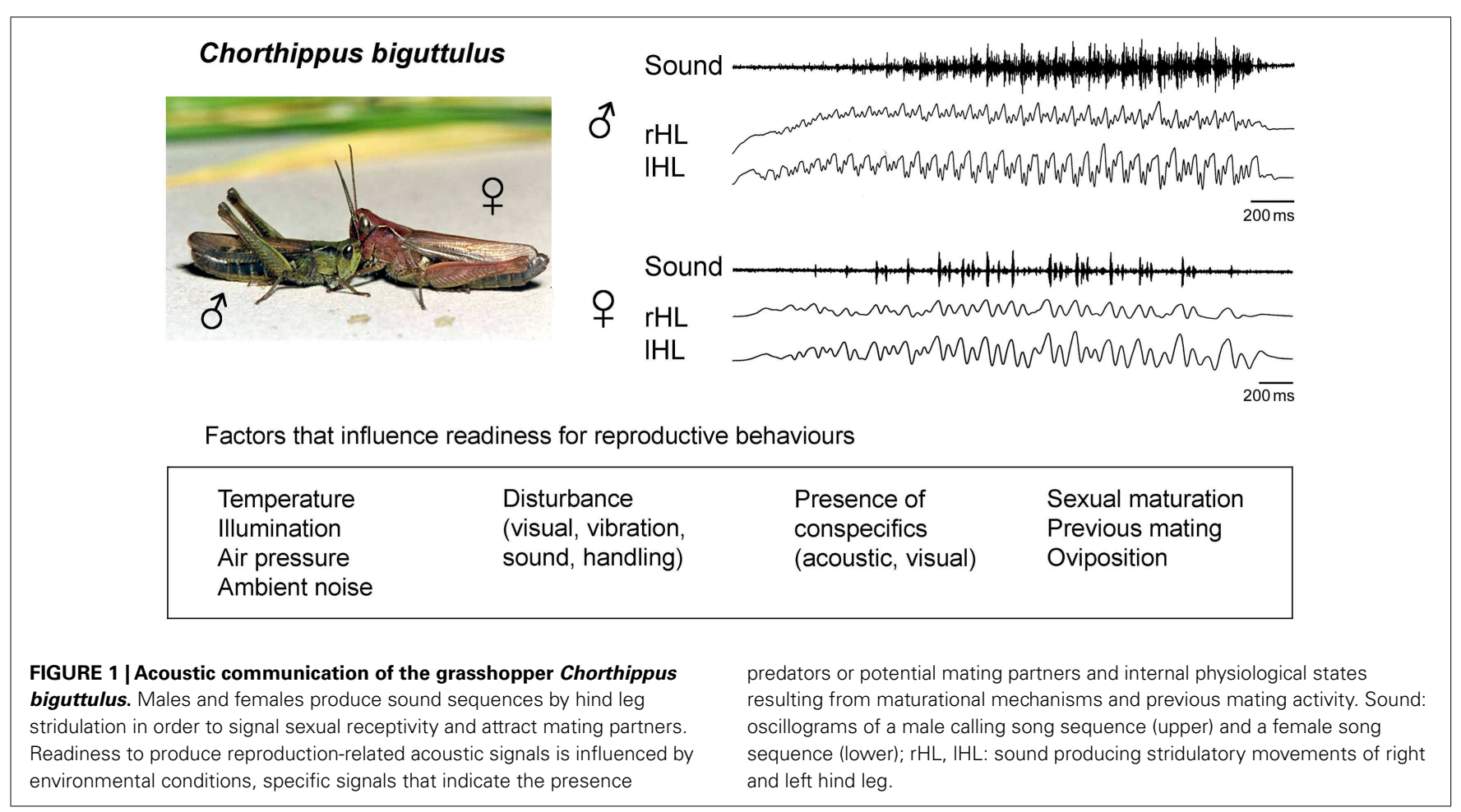




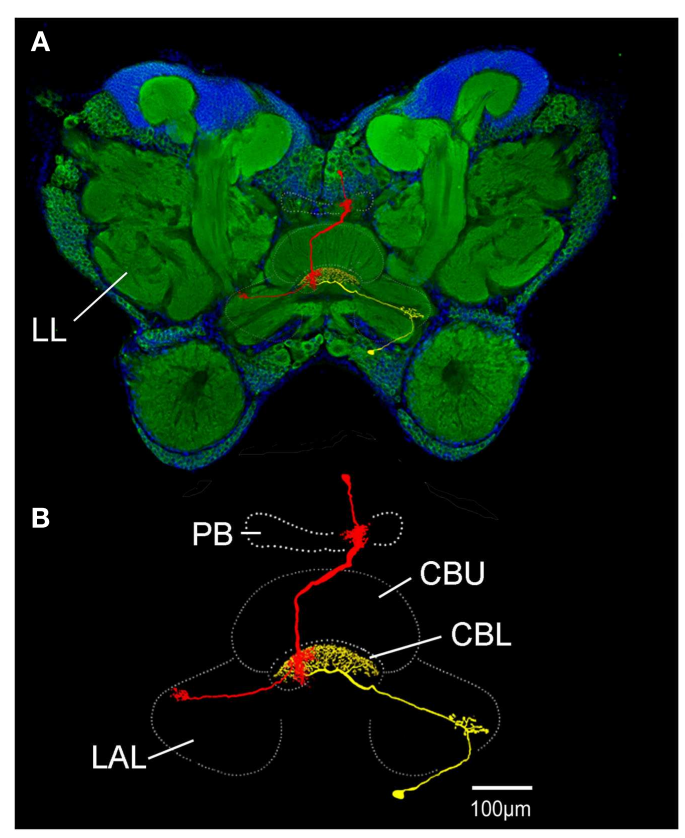

FIGURE 2 | Control of grasshopper sound production by the central complex. (A) Frontal section through a grasshopper brain labeled with the pan-neuronal marker anti-horse radish peroxidase (green fluorescence) and DAPI nuclear staining (blue fluorescence). (B) Innervation of central complex neuropils by one columnar (red) and one tangential neuron (yellow) with overlapping in- and output structures in the CBL. (C) Flow of information through the central complex related to the control of sound
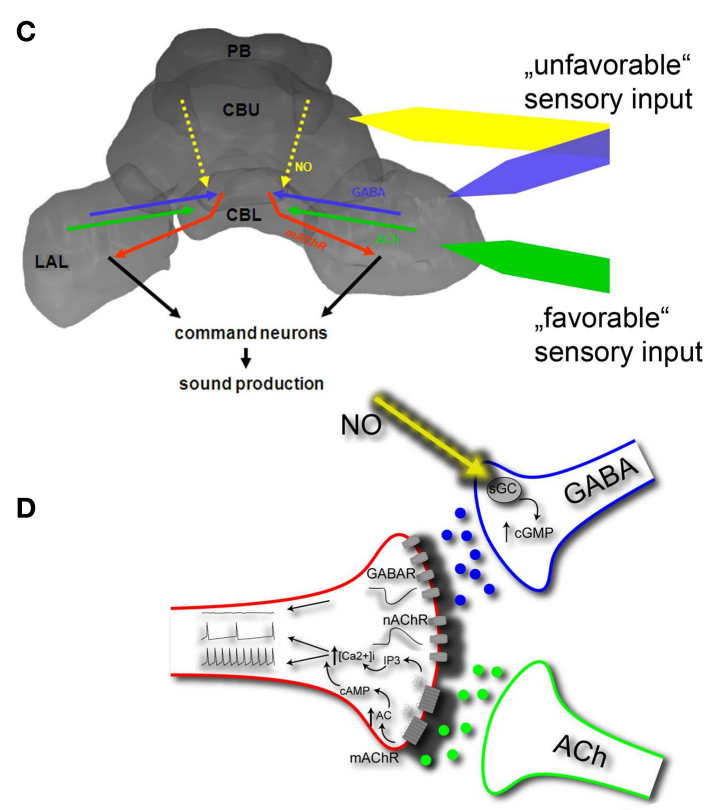

production. (D) Details of information processing in the CBL. See text for descriptions of (C,D). LL lateral protocerebral neuropil containing the neural filters for sound pattern recognition; PB protocerebral bridge; $\mathrm{CBU}$ central body upper division; $C B L$ central body lower division; LAL lateral accessory lobe; NO nitric oxide; $A C h$ acetylcholine; $n A C h R$ nicotinic $A C h$ receptor; mAChR muscarinic ACh receptor; $A C$ adenylyl cyclase; sGC soluble guanylyl cyclase. complex. Inhibition of chloride channel-associated receptors (e.g., $\mathrm{GABA}_{\mathrm{A}}$ - and glycine-receptors) by picrotoxin (Heinrich et al., 1998), inhibition of GABA production by 3-mercapto propionic acid and inhibition of nitric oxide formation by aminoguanidine (Weinrich et al., 2008) were sufficient to release sound production by disinhibition, though the typical activity-pause structure and the clear separation of situation-specific patterns was compromised in some species. Grasshopper sound production is therefore regulated by a balance of excitatory and inhibitory input to the central complex which reflects sensory stimuli that represent favorable and unfavorable situations for reproductive behaviors (Kunst et al., 2011). Integration of promoting and suppressing information might be a universal characteristic in central nervous regions that select motor patterns (reviewed by Benjamin et al., 2010), since similar regulatory mechanisms have also been described in vertebrates, e.g., control of locomotion in mesencephalic and diencephalic locomotory regions (Takakusaki, 2008) and the selection of voluntary motor pograms by the basal ganglia (Nambu, 2009) which serve similar functions in vertebrates as the central complex in insects (Wessnitzer and Webb, 2006; Stephenson-Jones et al., 2011).

The central complex of grasshoppers (Figure 2) includes four interconnected subunits: the protocerebral bridge, the upper and lower divisions of the central body, and the paired noduli (Williams, 1975; Homberg, 1987). Both divisions of the central body, which are of major importance for the control of sound production, consist of individual layers intersected by 16 columns
(Williams, 1975; Homberg, 1991). Layers derive from projections of groups of tangential neurons that provide input to all columns which mainly derives from the lateral accessory lobes. Columnar neurons connect the columns of the protocerebral bridge in regular ipsi- and contralateral projection patterns with those of the two central body neuropils and send information to the lateral accessory lobes, the major input/output neuropils of the central complex (Müller et al., 1997; Homberg et al., 2004). All columns include columnar neurons that express muscarinic acetylcholine receptors (mAChRs; Hoffmann et al., 2007; Kunst et al., 2011). Since no other neuron in the central complex expresses mAChRs, a subpopulation of these neurons must be directly activated when sound production is stimulated through muscarine injection into the central complex. With dendritic input regions in the lower division of the central body and synaptic terminals in the lateral accessory lobes, activity of the mAChR expressing columnar neurons seems to represent an output signal of the central complex that is sufficient (or even necessary?) to initiate sound production. It has been demonstrated that the mAChR expressing columnar neurons receive excitatory cholinergic input when grasshoppers are acoustically stimulated with songs from their own species. Male calling songs and female response songs signal high reproductive readiness and mediate strong stimulatory impact on a potential mating partner. Auditory information is first processed in the metathoracic ganglion and then relayed by ascending auditory interneurons to lateral protocerebral neuropils (LL in Figure 2) that include the neural filters for sound 
pattern recognition (Boyan, 1983; Hedwig, 1986). A neuron that could close the loop between acoustic stimulation and production of a response song was described by Hedwig (2001). It connected the lateral neuropils with the central protocerebrum and its activation by intracellular current application initiated sound production. Pharmacological studies demonstrated that $\mathrm{mAChR}$ mediated excitation depends on repetitive stimulation with either acoustic stimuli (Hoffmann et al., 2007) or injections of acetylcholine (Wenzel et al., 2002). At identical stimulation sites within the central complex muscarine elicits long lasting stridulation after long latencies while ACh elicits only short lasting stridulation after short latencies, representing pure nicotinic excitatory effects (Heinrich et al., 1997). Only when the presence of ACh was prolonged through repeated injections or inhibition of acetylcholine esterase, muscarinic excitation accumulated, and eventually stimulated response songs to acoustic stimulation with conspecific song even in restrained animals (Hoffmann et al., 2007). Muscarinic excitation of $\mathrm{mAChR}$ expressing columnar output neurons of the central complex, elicited by prolonged exposure to sensory stimuli which favor sound production, therefore represents a basal activity upon which specific actual stimuli may add to provide sufficient excitation to initiate song production. Grasshopper song production can also be stimulated by injection of proctolin or dopamine but specific sensory input that activates these excitatory inputs has not yet been identified.

In addition to direct cholinergic excitation of columnar neurons, activation of inhibitory pathways in the central complex has a strong regulatory impact on sound production. Especially two transmitters, nitric oxide (NO) and GABA, seem to be tonically released in situations where stridulation appears inappropriate. Such an unfavorable situation for reproduction-related behavior is certainly being restrained in an experimental setup for pharmacological brain stimulation. Consequently, neither male nor female grasshoppers spontaneously respond to acoustic stimulation with songs of a potential mating partner. However, song production can be elicited through disinhibition, either by preventing NO formation with the NO-synthase inhibitor aminoguanidine (Weinrich et al., 2008) or by the chloride channel-associated receptor antagonist picrotoxin (Heinrich et al., 1998). Furthermore, systemic application of aminoguanidine increased the responsiveness of unrestrained grasshoppers to conspecific song and suppressed NO-synthase activity in the central body, suggesting that endogenous $\mathrm{NO}$ signaling in the central complex regulates sound production by mediating inhibition that needs to be compensated by varying amounts of specific excitation to initiate stridulation (Weinrich et al., 2008). NO mediates its inhibition via activation of soluble guanylyl cyclase and the production of cyclic GMP in its target cells (Wenzel et al., 2005). In C. biguttulus and other acoustically communicating grasshopper species, NO-synthase expressing neurites, that generate and release NO into central complex neuropils were exclusively located in layers II and III of the central body upper division (Wenzel et al., 2005; Kunst et al., 2011). Most of these neurites belonged to pontine neurons with their cell bodies in the pars intercerebralis and some of them were tangential neurons with somata located in the inferior median protocerebrum. In contrast, NO-responsive neurites were restricted to layer II of the lower division of the central body, overlapping with the dendrites of $\mathrm{mAChR}$ expressing columnar neurons and projections of GABA containing tangential cells from the inferior protocerebrum that pick up synaptic input in the lateral accessory lobes. While the columnar output neurons of the central complex were excluded as direct targets of NO signaling, essentially all neurites that accumulated cyclic guanosine monophosphate (cGMP) upon NO stimulation in the lower division were also GABA immunoreactive (Kunst et al., 2011). These immunocytochemical data were supported by pharmacological experiments in which the $\mathrm{GABA}_{\mathrm{A}}$-receptor antagonist picrotoxin prevented NO-mediated inhibition of stridulation. NO released from neurites in the central body upper division thus mediates its suppressive effects on stridulation through the activation of GABAergic terminals in the lower division that in turn inhibit mAChR expressing columnar neurons (Figure 2). Both, cholinergic excitation that promotes sound production and nitrergic and GABAergic inhibition that suppress sound production converge on a group of columnar output neurons of the central complex whose cumulative activity initiates stridulation and probably other reproduction-related behaviors.

In addition to its global regulation of the behavioral threshold to initiate grasshopper stridulation, GABA plays an additional role in the selective execution of song patterns associated with particular situations. Inactivation of $\mathrm{GABA}_{\mathrm{A}}$-receptor mediated inhibition in the species Omocestus viridulus that produces different song patterns during the process of courtship, induced irregular mixtures of normally temporarily separated song patterns (Heinrich et al., 1998). Thus GABA-mediated inhibition assures the selective production of only one pattern at a time, by lateral inhibition of descending premotor pathways that regulate the activation of different thoracic pattern generators.

\section{"LONG-TERM" REGULATION OF GRASSHOPPER SOUND PRODUCTION BY JUVENILE HORMONE PRODUCTION IN THE CORPORA ALLATA}

Reproductive readiness is characterized by specific behaviors intended to find, compare, and eventually mate with an appropriate partner of the same species and its establishment may depend on various factors. In insects, these factors include sexual maturation, exposure to stimulating signals from a potential mating partner and previous mating experience. Various studies on the regulation of reproductive readiness have been conducted on acoustically communicating grasshoppers and female responses to male calling song or male responses to female songs have been used to quantify an individual's reproductive motivation (Loher, 1966; von Helversen and von Helversen, 1983; Weinrich et al., 2008). C. biguttulus males maturate within 1-2 days after their imaginal molt and produce calling songs to attract females throughout their lifetime, whenever illumination and weather conditions are appropriate. After copulating with a female, male calling song activity and male responses to female songs are reduced for $\sim 2$ days, indicating their reduced reproductive readiness for 2 days after mating (Wirmer et al., 2010). Females require post-molting maturation of 6-7 days ("primary rejection") before they first respond to male calling song (Figure 3A). If mating is prevented, this state of "active readiness" is retained throughout life, only interrupted by short periods of rejection around times of oviposition. Mating initiates 


\section{A Time [days]}

isolated
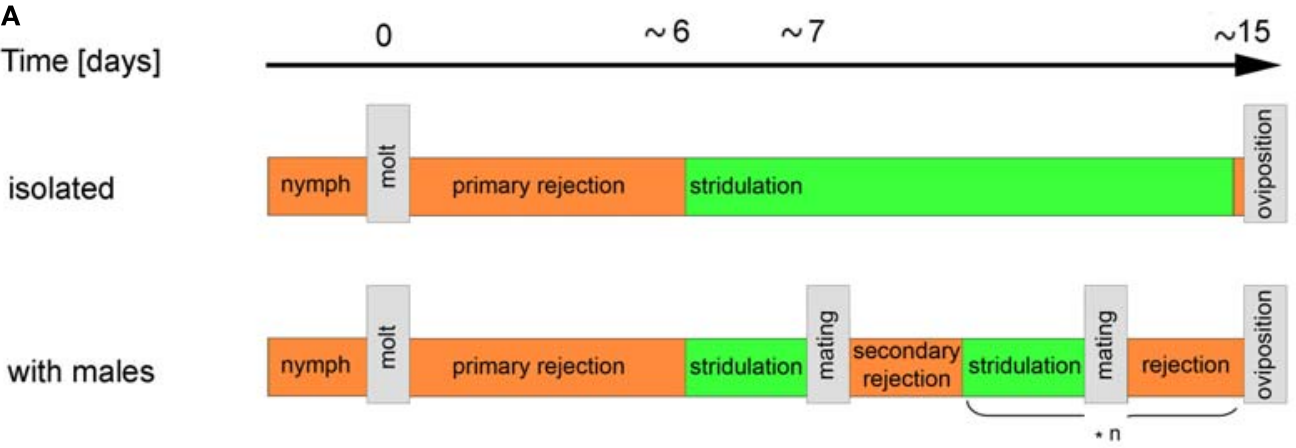

allatectomized
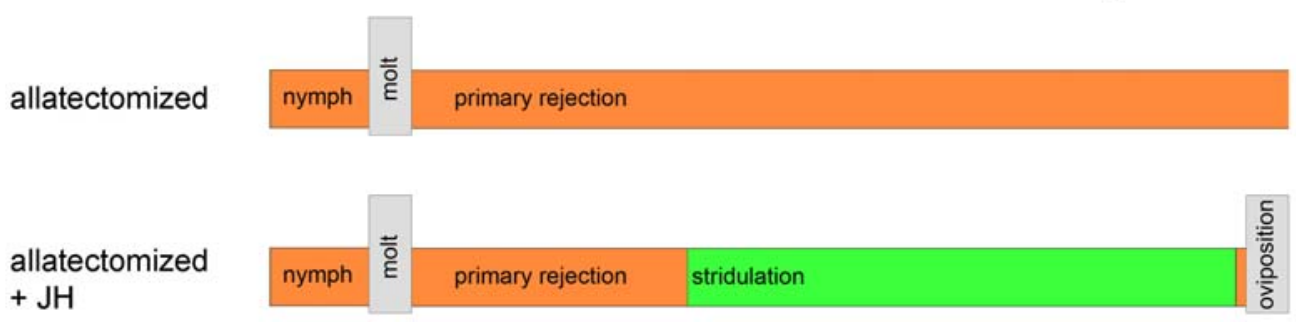

B

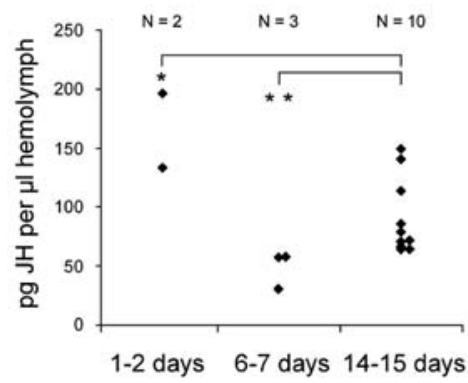

C

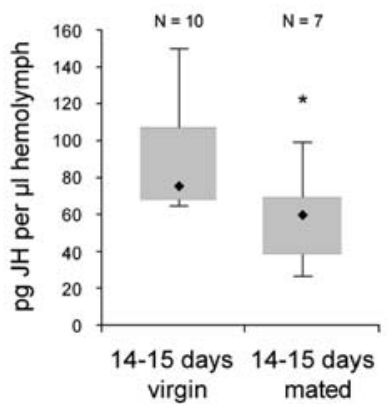

D

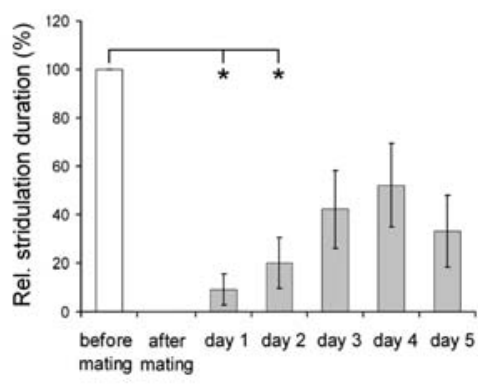

FIGURE 3 | Control of female $\boldsymbol{C}$. biguttulus reproduction-related sound production by juvenile hormone. (A) Reproductive states between imaginal molt and first oviposition. Allatectomy was performed within $24 \mathrm{~h}$ after imaginal molt. JH was diluted in acetone $(23 \mu \mathrm{g} \mathrm{JH} \mathrm{III} \mathrm{in} 5 \mu \mathrm{l}$ acetone) and applied to the ventral abdomen on day two after imaginal molt. Acetone alone had no effect on female reproductive behavior. (B) JH III titer in the hemolymph of virgin females in different reproductive states. $\mathrm{JH}$ concentrations were determined by radioimmunoassay following protocols of
Hunnicutt et al. (1989) and Chen et al. (2007). Statistical comparison with Fisher-Pitman test. (C) JH III titer in the hemolymph of virgin and mated (1 day before analysis) females. Statistical comparison with non-parametric Mann-Whitney- $U$-test. (D) Relative duration of male song-stimulated sound production in eight females before mating, immediately after mating, and on five subsequent days. Statistical analysis with Friedman test and Wilcoxon-Wilcox test). Parts of the figure were taken from Wirmer et al. (2010). a period of "secondary rejection" followed by re-establishment of active readiness. C. biguttulus show reduced responsiveness to male calling songs for up to 2 days and may pass several cycles of active readiness, copulation, and secondary rejection before their first oviposition (Figures 3A,D; Wirmer et al., 2010).

Establishment of female grasshopper active copulatory readiness critically depends on $\mathrm{JH}$ signaling. $\mathrm{JH}$, a key regulator of insect development and reproduction (reviewed by Riddiford, 2008), is produced and released by parenchymal cells of the corpora allata and transported via the hemolymph to its target tissues, that include the ovaries and the nervous system (Emmerich and Hartmann, 1973; Pratt and Tobe, 1974). Direct effects of JH on reproductive biology of insect females have been documented in grasshoppers (Hartmann et al., 1994), cockroaches (Schal et al., 1997), and honeybees (Huang et al., 1991). Female grasshoppers that lack JH after surgical or chemical ablation of the corpora allata (allatectomy) never respond to male calling songs and lifelong refuse to mate with a male (Loher, 1962; own studies), indicating that $\mathrm{JH}$ signaling is necessary to establish reproductive readiness. A single application of exogenous $\mathrm{JH}$ to allatectomized C. biguttulus females 1 day after imaginal molt partially rescued the lack of reproductive behaviors. Females started to answer male calling songs at the typical age of 6-7 days but did not mate until first oviposition (Figure 3A; unpublished results). Radioimmunoassay analysis of $\mathrm{JH}$ hemolymph contents in different reproductive states of $C$. biguttulus females revealed high concentrations around the time of imaginal molting, low concentrations around the time of transition from primary rejection to active readiness (6-7 days) and intermediate titers in females approaching the age of their first oviposition (Figure 3B). These data are in agreement with studies of Hartmann et al. (1994) who determined the rates of JH synthesis in corpora allata from Gomphocerus rufus females 
in different reproductive states and similar time courses of $\mathrm{JH}$ titers were also detected in the cricket Gryllus bimaculatus (Westerlund, 2004) and the corn borer Diatraea grandiosella (Shu et al., 1997) but differences have been reported in Locusta migratoria (Dale and Tobe, 1986) and the cockroach Diploptera punctata (Tobe et al., 1985). One day after mating JH titers were significantly reduced (by $\sim 20 \%$ ) in 14-15 days old C. biguttulus females (Figure 3C) going along with reduction of responsiveness to male calling songs described above (Figure 3D). Effects of mating on $\mathrm{JH}$ synthesis were also reported from moths, flies, and cockroaches but in contrast to grasshopper females, JH production increased in these insects (Gadot et al., 1991; Moshitzky et al., 1996; Schal et al., 1997; Cusson et al., 1999).

Taking all available results together, $C$. biguttulus females seem to require a high concentration of $\mathrm{JH}$ at the beginning of adulthood to initiate maturation of ovaries and probably other organs involved in reproduction but require lower $\mathrm{JH}$ titers to activate reproductive behaviors that characterize active readiness, including sound production and copulation. Both reduction and elevation of this permissive $\mathrm{JH}$ concentration, probably modulated by mating and oviposition go along with lower female reproductive readiness, though a causal regulatory connection has not yet been demonstrated. Male-derived accessory gland proteins transferred to the female during copulation may also contribute to reduce sexual receptivity of females after mating (Hartmann and Loher, 1999; Ram and Wolfner, 2007).

\section{REGULATION OF REPRODUCTION-RELATED SOUND PRODUCTION BY BRAIN AND CORPORA ALLATA}

Sound production and other behaviors that promote reproduction should only be initiated when both the reproductive physiological state and the actual situation are appropriate. As described above, the same sensory signals that initiate sound production and mating in male and especially female grasshoppers during active readiness are insufficient during rejective states. Since female reproductive states are at least partly mediated by JH signaling, humoral signals may directly or indirectly modulate neural processing in brain regions that control sound production and mating.

$\mathrm{JH}$ production by the corpora allata is regulated by the brain. Protocerebral neurons that innervate the corpora allata via the nervi corporis allati I have been identified in the pars intercerebralis and pars lateralis regions of various insects (Moore and Loher, 1988; Virant-Doberlet et al., 1994; Vullings et al., 1999). Whether these neurons activate or inhibit $\mathrm{JH}$ production seems to be different among species as are the chemical signals (summarized as allatotropins and allatostatins) that mediate this regulation (Tobe and Stay, 1980; Kataoka et al., 1989; Horseman et al., 1994; Bräunig et al., 1996; Gilbert et al., 2000; Weaver and Audsley, 2009). Each corpus allatum of C. biguttulus is innervated by $80-90$ pars intercerebralis and pars lateralis neurons and approximately half of these release RFamide from varicose terminals (Figure 4; Wirmer and Heinrich, 2011; unpublished results). RFamides have been demonstrated to mediate excitatory and inhibitory effects via a number of different ionotropic and metabotropic receptors (Kobayashi and Muneoka, 1989; Cazzamali and Grimmelikhuijzen, 2002). RFamide is suggested to stimulate parenchymal cells in the corpora allata since intact brain to corpora allata connections

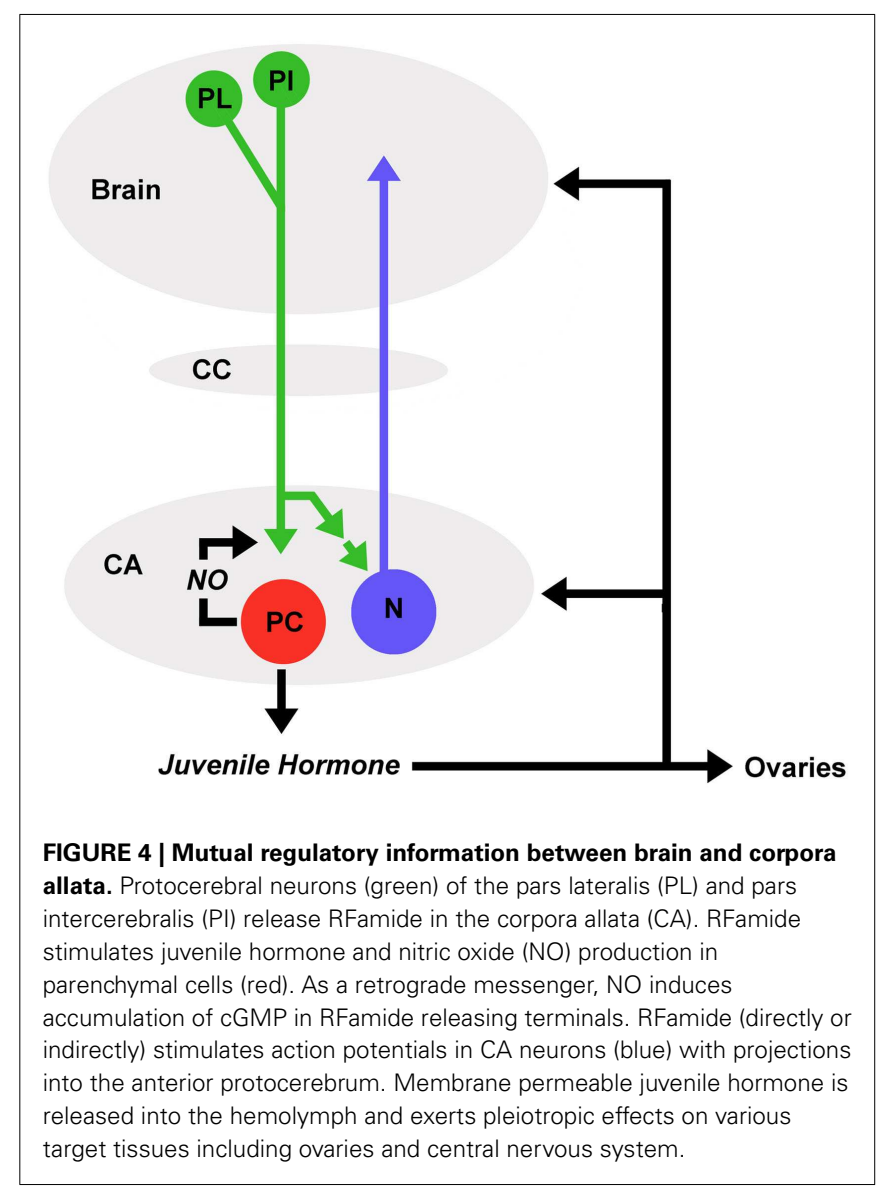

are required to maintain $\mathrm{JH}$ production in locusts (Tobe et al., 1977), oscillations of RFamide immunoreactivity correlated with changes in JH titers in locusts (Sevala et al., 1993) and RFamide stimulated $\mathrm{JH}$ production in some reproductive states in a cockroach (Stay et al., 2003). Prolonged courtship may actually alter the hormonal state of grasshopper females, mediating increased reproductive readiness. In species like G. rufus, C. curtipennis, females assume a state of "passive readiness" during which they do not stridulate but allow copulation after prolonged male courtship, which may last more than $1 \mathrm{~h}$. A study by Riede (1983) demonstrated that exposure of G. rufus females to male courtship song advanced the age of first copulations compared to the start of "active readiness," suggesting that altered hormonal state may change a females behavioral response to male courtship. Whether effects like this could be mediated through activation of neurosecretory pars intercerebralis or pars lateralis neurons that modulate hormonal release from the retrocerebral complex remains to be explored.

In C. biguttulus, RFamide seems to stimulate both $\mathrm{JH}$ production and generation of NO by parenchymal cells (unpublished results). NO stimulates the formation of cyclic GMP in the terminals of RFamide releasing neurons, suggesting that it acts as a retrograde signal that modulates subsequent release of RFamide (Figure 4; Wirmer and Heinrich, 2011). In addition, RFamide also stimulates neurons located in the corpora allata that have recently been identified by immunocytochemistry against neuron-specific 
markers in C. biguttulus (Wirmer and Heinrich, 2011; unpublished results) and were suggested to exist by earlier studies on other insects (McQuiston and Tobe, 1991). Anatomical studies on locusts revealed that each corpus allatum contains less than 50 neurons and at least 24 of them, that where backfilled in the same preparation from an incision into the median bundle in the protocerebrum, project into anterior portions of the brain (Figure 4; Wirmer et al., unpublished). While the postsynaptic targets of these neurons are still unknown, electrophysiological recordings from the nervus corporis allatum I demonstrated that their axons propagate action potentials from the corpora allata to the brain. These neurons could in principle modulate the sensory-motor processing relevant for reproductive behaviors and potentially adjust their initiation thresholds to the activity state of the $\mathrm{JH}$ producing corpora allata.

In addition to neuronal regulation, brain functions may also be modulated by $\mathrm{JH}$ or other humoral factors associated with the regulation of reproductive states. JH titers have been demonstrated to regulate $\mathrm{JH}$ production by the corpora allata. As one example, reduced titers resulting from ablation of one corpus allatum or enhanced titers resulting from implantation of additional corpora allata are compensated by enhanced $\mathrm{JH}$ production of the remaining secretory organs of the host (Tobe and Stay, 1980). In locusts, this compensatory response requires intact brain to corpora allata connections, suggesting that $\mathrm{JH}$ mediates its regulatory effects on corpora allata activity indirectly via effects on brain neurons (Tobe et al., 1977; Cassier, 1979). JH is a membrane permeable messenger that binds to a large number of proteins including carriers, enzymes, membrane bound receptors, and nuclear receptors that may initiate long-term changes of cellular physiology through transcriptional regulation (reviewed by Wheeler and Nijhout, 2003). Direct actions on neuronal processing and the modulation of phonotactic mate localization have been documented in female crickets (Stout et al., 1991). By altering transcription, JH reduced the activation threshold of an ascending interneuron that carries auditory information from thoracic neuropils to the lateral protocerebrum, where neural filters for sound pattern recognition are localized.

Juvenile hormone stimulates maturation, vitellogenesis, and activity of insect ovaries (Loher, 1966; Sroka and Gilbert, 1971). In a stage-specific manner, ovaries produce and secrete peptidergic signals into the hemolymph that stimulate $\mathrm{JH}$ release from the CA (Elliott et al., 2006) and may exert additional physiological effects on other organs.

\section{REFERENCES}

Benjamin, P. R., Staras, K., and Kemenes, G. (2010). What role do tonic inhibition and disinhibition play in the control of motor programs? Front. Behav. Neurosci. 4:30, doi:10.3389/fnbeh.2010.00030

Boyan, G. S. (1983). Postembryonic development in the auditory system of the locust. Anatomical and physiological characterisation of interneurones to the brain. J. Comp. Physiol. A 151, 499-513.
Bräunig, P., Böhme, C., and Staufer, B. (1996). Morphology of locust neurosecretory cells projecting into the nervus corporis allati II of the subesophageal ganglion. Microsc. Res. Tech. 35, 230-241.

Cassier, P. (1979). The corpora allata of insects. Int. Rev. Cytol. 57, $1-73$.

Cazzamali, G., and Grimmelikhuijzen, C. J. P. (2002). Molecular cloning and functional expression of the

Though some factors that regulate reproductive readiness and the initiation of components of mating behavior have been characterized in acoustically communicating grasshoppers (and some other insect species) our understanding about the interplay of endogenous maturational and exogenous situation-specific signals that converge to generate a coherent state of readiness is still rudimentary. All regulatory components, including the central complex and the corpora allata are known to contain various additional players. The central complex is known to be innervated by neurons that release a huge variety of chemical signals and only a fraction of these have been tested for a potential contribution to the regulation of reproductive behaviors. The central complex in orthopteran insects has been shown to receive pre-processed sensory information of various modalities, including acoustic (this review), visual (Vitzthum et al., 2002), and tactile (Ritzmann et al., 2008). In addition, both acoustic and chemical signals have been demonstrated to initiate and promote courtship in Drosophila melanogaster (reviewed by Greenspan and Ferveur, 2000). Since males of some grasshopper species include rhythmic movements of head, antennae, and mouthparts in their courtship and assume particular postures during its progress (Elsner and Huber, 1969: G. rufus; Vedenina et al., 2007: C. oshei) and highly receptive female grasshoppers may stridulate upon seeing a male (Loher and Huber, 1964) it can be assumed that species and/or gender specific visual signals modulate the progress of courtship and hence must be integrated with auditory information. One study on G. rufus (Elsner and Huber, 1969) indicates that female-associated optical, acoustic, and tactile stimuli promote male courtship behavior while chemical input (touching male antennae with parts of a female) had no effect on the male. Although the promoting impact of specific visual, tactile, and chemical signals on grasshopper courtship is not well investigated, it is clear that acoustic, visual, and tactile stimuli can suppress or interrupt courtship behavior, indicating that their nervous representations are relayed to the central complex.

In addition to RFamide releasing neurons, grasshopper corpora allata are innervated by protocerebral proctolin containing neurons and allatostatin containing terminals of unknown source, suggesting that the local processing of information in the corpora allata is more complex than described above. Future studies will first investigate each factor individually for its role in the regulation of reproductive readiness and the selection of state-dependent actions and subsequently determine how individual factors converge on decisive nervous structures that activate adequate motor programs.

first insect FMRFamide receptor. Proc. Natl. Acad. Sci. U.S.A. 99, 12073-12078.

Chen, Z., Linse, K. D., TaubMontemayor, T. E., and Rankin, M. A. (2007). Comparison of radioimmunoassay and liquid chromatography tandem mass spectrometry for determination of juvenile hormone titers. Insect Biochem. Mol. Biol. 37, 799-807.

Cusson, M., Delisle, J., and Miller, D. (1999). Juvenile hormone titers in virgin and mated Choristoneura fumiferana and C. rosaceana females: assessment of the capacity of males to produce and transfer $\mathrm{JH}$ to the female during copulation. J. Insect Physiol. 45, 637-646.

Dale, J. F., and Tobe, S. S. (1986). Biosynthesis and titre of juvenile hormone during the first gonotrophic cycle in isolated and crowded Locusta migratoria females. J. Insect Physiol. 32, 763-769. 
Elliott, K. L., Woodhead, A. P., and Stay, B. (2006). A stage-specific ovarian factor with stable stimulation of juvenile hormone synthesis in corpora allata of the cockroach Diploptera punctata. J. Insect Physiol. 52, 929-935.

Elsner, N. (1974). Neuroethology of sound production in gomphocerine grasshoppers. I. Song patterns and stridulatory movements. J. Comp. Physiol. A 88, 67-102.

Elsner, N., and Huber, F. (1969). The effects of changes in central and peripheral conditions on the organization of courtship song in the grasshopper Gomphocerippus rufus L. Z. Vgl. Physiol. 65, 389-423.

Elsner, N., and Wasser, G. (1995). Leg and wing stridulation in various populations of the gomphocerine grasshopper Stenobothrus rubicundus (Germar 1817), I. Sound patterns and singing movements. Zoology 98, 179-190.

Emmerich, H., and Hartmann, R. (1973). A carrier lipoprotein for juvenile hormone in the haemolymph of Locusta migratoria. J. Insect Physiol. 19, 1663-1675.

Gadot, M., Chiang, A.-S., Burns, E. L., and Schal, C. (1991). Cyclic juvenile hormone biosynthesis in the cockroach, Blattella germanica: effects of ovariectomy and corpus allatum denervation. Gen. Comp. Endocrinol. $82,163-171$.

Gilbert, L. I., Granger, N. A., and Roe, R. M. (2000). The juvenile hormones: historical facts and speculations on future research directions. Insect Biochem. Mol. Biol. 30, 617-644.

Greenspan, R. J., and Ferveur, J.-F. (2000). Courtship in Drosophila. Annu. Rev. Genet. 34, 205-232.

Hartmann, R., and Loher, W. (1999). Post-mating effects in the grasshopper Gomphocerus rufus L. mediated by the spermatheca. J. Comp. Physiol. A 184, 325-332.

Hartmann, R., Loher, W., and Huber, F. (1994). Correlation between the rate of juvenile hormone biosynthesis in vitro and sexual behavior patterns in Gomphocerus rufus females. Naturwissenschaften 81, 40-41.

Hedwig, B. (1986). On the role in stridulation of plurisegmental interneurons of the acridid grasshopper Omocestus viridulus L. J. Comp. Physiol. A 158, 429-444.

Hedwig, B. (1992). On the control of sridulation in the acridid grasshopper Omocestus viridulus L. I. Interneurons involved in rhythm generation and bilateral coordination. J. Comp. Physiol. A $171,117-128$

Hedwig, B. (1994). A cephalothoric command system controls stridulation in the acridic grasshopper $\mathrm{Omo}$ cestus viridulus. J. Neurophysiol. 72, 2015-2025.

Hedwig, B. (2001). Singing and hearing: neuronal mechanisms of acoustic communication in Orthopterans. Zoology 103, 140-149.

Hedwig, B., and Heinrich, R. (1997). Identified descending brain neurons control different stridulatory motor patterns in an acridid grasshopper. $J$. Comp. Physiol. A 180, 285-294.

Heinrich, R., and Elsner, N. (1997). On the central nervous control of hindleg coordination in stridulating grasshoppers. J. Comp. Physiol. A 180, 257-269.

Heinrich, R., Hedwig, B., and Elsner, N. (1997). Cholinergic activation of stridulatory behaviour in the grasshopper Omocestus viridulus (L.). J. Exp. Biol. 200, 1327-1337.

Heinrich, R., Rozwod, K., and Elsner, N. (1998). Neuropharmacological evidence for inhibitory cephalic control mechanisms of stridulatory behaviour in grasshoppers. J. Comp. Physiol. A 183, 389-399.

Heinrich, R., Wenzel, B., and Elsner, N. (2001). Pharmacological brain stimulation releases elaborate stridulatory behaviour in gomphocerine grasshoppers - conclusions for the organisation of the central nervous control. J. Comp. Physiol. A 180, 257-269.

Hoffmann, K., Wirmer, A., Kunst, M., Gocht, D., and Heinrich, R. (2007). Muscarinic excitation in grasshopper song control circuits is limited by acetylcholinesterase activity. Zool. Sci. 24, 1028-1035.

Homberg, U. (1987). "Structure and function of the central complex in insects," in Arthropod Brain: Its Evolution, Development, Structure and Functions, ed. A. P. Gupta (New York: Wiley), 347-367.

Homberg, U. (1991). Neuroarchitecture of the central complex in the brain of the locust Schistocerca gregaria and S. americana as revealed by serotonin immunocytochemistry. J. Comp. Neurol. 303, 245-254.

Homberg, U., Brandl, C., Clynen, E., Schoofs, L., and Veenstra, J. A. (2004). Mas-allatotropin/lomAGmyotropin I immunostaining in the brain of the locust, Schistocerca gregaria. Cell Tissue Res. 318, 439-457.

Horseman, G., Hartmann, R., VirantDoberlet, M., Loher, W., and Huber, F. (1994). Nervous control of juvenile hormone biosynthesis in Locusta migratoria. Proc. Natl. Acad. Sci. U.S.A. 91, 2960-2964.

Huang, Z.-Y., Robinson, G. E., Tobe, S. S., Yagi, K. J., Strambi, C., Strambi, A., and Stay, B. (1991). Hormonal regulation of behavioural development in the honey bee is based on changes in the rate of juvenile hormone biosynthesis. J. Insect Physiol. 37, 733-741.

Hunnicutt, D., Toong, Y. C., and Borst, D. W. (1989). A chiral specific antiserum for juvenile hormone. Am. Zool. 29, 48a.

Kataoka, H., Toschi, A., Li, J. P., Carney, R. L., Schooley, D. A., and Kramer, S. J. (1989). Identification of an allatotropin from adult Manduca sexta. Science 243, 1481-1483.

Kobayashi, M., and Muneoka, Y. (1989). Functions, receptors, and mechanisms of the FMRFamide related peptides. Biol. Bull. 177, 206-209.

Kriegbaum, H. (1988). Untersuchungen zur "Lebensgeschichte" von Feldheuschrecken (Acrididae, Gomphocerinae): Fortpflanzungsstrategie und akustisches Verhalten im natürlichen Habitat. Ph.D. thesis, University of Erlangen, Erlangen.

Kunst, M., Pförtner, R., Aschenbrenner, K., and Heinrich, R. (2011). Neurochemical architecture of the central complex related to ist function in the control of grasshopper acoustic communication. PLoS ONE 6, e25613. doi:10.1371/journal.pone.0025613

Loher, W. (1962). Die Kontrolle des Weibchengesanges von Gomphocerus rufus L. (Acridinae) durch die Corpora allata. Naturwissenschaften 49, 406.

Loher, W. (1966). Die Steuerung sexueller Verhaltensweisen und der Oocytenentwicklung bei Gomphocerus rufus L. Z. Vgl. Physiol. 53, 277-316.

Loher, W., and Huber, F. (1964). Experimentelle Untersuchungen am Sexualverhalten des Weibchens der Heuschrecke Gomphocerus rufus L. (Acridinae). J. Insect Physiol. 10, 13-36.

Lorier, E., Clemente, M. E., Garcia, M. D., and Presa, J. J. (2010). Acoustic behaviour of Fenestra bohlsii GiglioTos (Orthoptera: Acrididae: Gomphocerinae). Neotrop. Entomol. 30 839-853.

McQuiston, A. R., and Tobe, S. S (1991). Evidence for a calciumdependent outward conductance in endocrine cells of the cockroach, Diploptera punctata. Physiol. Entomol. 16, 429-433.
Moore, D., and Loher, W. (1988). Axonal projections within the brainretrocerebral complex of the cricket, Teleogryllus commodus. Cell Tissue Res. 252, 501-514.

Moshitzky, P., Fleischmann, I., Chaimov, N., Saudan, P., Klauser, S., Kubli, E., and Applebaum, S. W. (1996). Sex-peptide activates juvenile hormone biosynthesis in the Drosophila melanogaster corpus allatum. Arch. Insect Biochem. Physiol. 32, 363-374.

Müller, M., Homberg, U., and Kühn, A. (1997). Neuroarchitecture of the lower division of the central body in the brain of the locust (Schistocerca gregaria). Cell Tissue Res. 288, 159-176.

Nambu, A. (2009). Seven problems on the basal ganglia. Curr. Opin. Neurobiol. 18, 595-604.

Popov, A. V., Peresleni, A. I., Ozerskii, P. V., Shchekanov, E. E., and SawateevaPopova, E. V. (2005). The role of the flabellar and ellipsoid bodies of the central complex of the brain of Drosophila melanogaster in the control of courtship behavior and communicative sound production in males. Neurosci. Behav. Physiol. 35 , 741-750.

Pratt, G. E., and Tobe, S. S. (1974). Juvenile hormones radiobiosynthesised by corpora allata of adult female locusts in vitro. Life Sci. 14, 575-586.

Ram, K. R., and Wolfner, M. F. (2007). Seminal influences: Drosophila Acps and the molecular interplay between males and females during reproduction. Integr. Comp. Biol. 47, 427-445.

Riddiford, L. M. (2008). Juvenile hormone action: a 2007 perspective. $J$. Insect Physiol. 54, 895-901.

Riede, K. (1983). Influence of the courtship song of the acridid grasshopper Gomphocerus rufus L. on the female. Behav. Ecol. Sociobiol. (Print) 14, 21-27.

Ritzmann, R. E., Ridgel, A. L., and Pollack, A. J. (2008). Multi-unit recording of antennal mechano-sensitive units in the central complex of the cockroach, Blaberus discoidalis. I. Comp. Physiol. A 194, 341-360.

Ronacher, B. (1989). Stridulation of acridid grasshoppers after hemisection of thoracic ganglia: evidence for hemiganglionic oscillators. J. Comp. Physiol. A 164, 723-736.

Schal, C., Holbrook, G. L., Bachmann, J. A. S., and Sevala, V. L. (1997). Reproductive biology of the German cockroach, Blattella germanica: juvenile hormone as a pleiotropic master regulator. Arch. Insect Biochem. Physiol. $35,405-426$. 
Sevala, V. M., Sevala, V. L., and Loughton, B. G. (1993). FMRFamide-like activity in the female locust during vitellogenesis. J. Comp. Neurol. 337, 286-294.

Shu, S., Park, Y. I., Ramaswamy, S. B., and Srinivasan, A. (1997). Hemolymph juvenile hormone titers in pupal and adult stages of southwestern corn borer [Diatraea grandiosella (Pyralidae)] and relationship with egg development. J. Insect Physiol. 43, 719-726.

Sroka, P., and Gilbert, L. I. (1971). Studies on the endocrine control of postemergence ovarian maturation in Manduca sexta. J. Insect Physiol. 17, 2409-2419.

Stay, B., Zhang, J. R., Kwok, R. D., and Tobe, S. S. (2003). Localization and physiological effects of RFamides in the corpora allata of the cockroach Diploptera punctata in relation to allatostatins. Peptides 24, 1501-1510.

Stephenson-Jones, M., Samuelsson, E., Ericsson, J., Robertson, B., and Grillner, S. (2011). Evolutionary conservation of the basal ganglia as a common vertebrate mechanism for action selection. Curr. Biol. 21, 1081-1091.

Stout, J., Atkins, G., and Zacharias, D. (1991). Regulation of cricket phonotaxis through hormonal control of the threshold of an identified auditory neuron. J. Comp. Physiol. A 169, 565-772.

Takakusaki, K. (2008). Forebrain control of locomotor behaviors. Brain Res. Rev. 57, 192-198.

Tobe, S. S., Chapman, C. S., and Pratt, G. E. (1977). Decay in juvenile hormone biosynthesis by insect corpus allatum after nerve transaction. Nature 268, 728-730.

Tobe, S. S., Ruegg, R. P., Stay, B. A., Baker, F. C., Miller, C. A., and Schooley, D. A. (1985). Juvenile hormone titre and regulation in the cockroach Diploptera punctata. Cell. Mol. Life Sci. 41, 1028-1034.
Tobe, S. S., and Stay, B. (1980). Control of juvenile hormone biosynthesis during the reproductive cycle of a viviparous cockroach: III. Effects of denervation and age on compensation with unilateral allatectomy and supernumerary corpora allata. Gen. Comp. Endocrinol. 40, 89-98.

Vedenina, V. Y., Panyutin, A. K., and von Helversen, O. (2007). The unusual inheritance pattern of the courtship songs in closely related grasshopper species of the Chorthippus albomarginatus-group (Orthoptera: Gomphocerinae). J. Evol. Biol. 20, 260-277.

Virant-Doberlet, M., Horseman, G., Loher, W., and Huber, F. (1994). Neurons projecting from the brain to the corpora allata in orthopteroid insects: anatomy and physiology. Cell Tissue Res. 277, 39-50.

Vitzthum, H., Müller, M., and Homberg, U. (2002). Neurons of the central complex of the locust Schistocerca gregaria are sensitive to polarized light. J. Neurosci. 22, 1114-1125.

von Helversen, D. (1972). Gesang des Männchens und Lautschema des Weibchens bei der Feldheuschrecke Chorthippus biguttulus (Orthoptera, Acrididae). J. Comp. Physiol. A 81, 381-422.

von Helversen, D., and von Helversen, O. (1975). Verhaltensgenetische Untersuchungen am akustischen Kommunikationssystem der Feldheuschrecken (Orthoptera, Acrididae) I. Der Gesang von Artbastarden zwischen Chorthippus biguttulus und Chorthippus mollis. J. Comp. Physiol. A 104, 273-299.

von Helversen, D., and von Helversen, O. (1983). "Species recognition and acoustic localization in acridid grasshoppers: a behavioral approach," in Neuroethology and Behavioral Physiology eds F. Huber and H. Markl (Berlin: SpringerVerlag), 95-107. von Helversen, D., and von Helversen, O. (1997). Recognition of sex in the acoustic communication of the grasshopper Chorthippus biguttulus (Orthoptera, Acrididae). J. Comp. Physiol. A 180, 373-386.

Vullings, H. G. B., Diederen, J. H. B. Veelaert, D., and Van den Horst, D. J. (1999). Multifactorial control of the release of hormones from the locust retrocerebral complex. Microsc. Res. Tech. 45, 142-153.

Weaver, R. J., and Audsley, N. (2009). Neuropeptide regulators of juvenile hormone synthesis. Structures, functions, distribution, and unanswered questions. Ann. N. Y. Acad. Sci. 1163, 316-329.

Weinrich, A., Kunst, M., Wirmer, A. Holstein, G. R., and Heinrich, R. (2008). Suppression of grasshopper sound production by nitric oxidereleasing neurons of the central complex. J. Comp. Physiol. A 194, 763-776.

Wenzel, B., Elsner, N., and Heinrich, R. (2002). mAChRs in the grasshopper brain mediate excitation by activation of the AC/PKA and the PLC second messenger pathways. J. Neurophysiol. 87, 876-888.

Wenzel, B., Kunst, M., Günther, C., Ganther, G. K., Lakes-Harlan, L., Elsner, N., and Heinrich, R. (2005). Nitric oxide/cyclic guanosine monophosphate signaling in the central complex of the grasshopper brain inhibits singing behavior. J. Comp. Neurol. 488, 129-139.

Wessnitzer, J., and Webb, B. (2006). Multimodal sensory integration in insects - towards insect brain control architectures. Bioinspir. Biomim. 1, 63-75.

Westerlund, S. (2004). Measuring Juvenile Hormone and Ecdysteroid Titer in Insect Haemolymph Simultaneously by LC-MS: the Basis for Determining the Effectiveness of PlantDerived Alkaloids and Insect Growth Regulators. Ph.D. thesis, University of Bayreuth, Bayreuth.
Wheeler, D. E., and Nijhout, H. F. (2003). A perspective for understanding the modes of juvenile hormone action as a lipid signaling system. Bioessays 25, 994-1001.

Williams, J. L. D. (1975). Anatomical studies of the insect central nervous system: a ground-plan of the midbrain and an introduction to the central complex in the locust, Schistocerca gragaria (Orthoptera). J. Zool. 76, 67-86.

Wirmer, A., Faustmann, M., and Heinrich, R. (2010). Reproductive behaviour of female Chorthippus biguttulus grasshoppers. J. Insect Physiol. 56, 745-753.

Wirmer, A., and Heinrich, R. (2011). Nitric oxide/cGMP signalling in the corpora allata of female grasshoppers. J. Insect Physiol. 57, 94-107.

Conflict of Interest Statement: The authors declare that the research was conducted in the absence of any commercial or financial relationships that could be construed as a potential conflict of interest.

Received: 02 January 2012; paper pending published: 04 May 2012; accepted: 29 May 2012; published online: 25 June 2012.

Citation: Heinrich $R$, Kunst $M$ and Wirmer A (2012) Reproduction-related sound production of grasshoppers regulated by internal state and actual sensory environment. Front. Neurosci. 6:89. doi: 10.3389/fnins.2012.00089

This article was submitted to Frontiers in Decision Neuroscience, a specialty of Frontiers in Neuroscience.

Copyright (c) 2012 Heinrich, Kunst and Wirmer. This is an open-access article distributed under the terms of the Creative Commons Attribution Non Commercial License, which permits noncommercial use, distribution, and reproduction in other forums, provided the original authors and source are credited. 